MATEC Web of Conferences 48,01006 (2016)

DOI: $10.1051 /$ matecconf $/ 20164801006$

C Owned by the authors, published by EDP Sciences, 2016

\title{
Designing of space oriented body parts with the use of modern technologies
}

\author{
Munkhe-Zul Ayusheev ${ }^{1, a}$ and Tamara Kostyuchenko ${ }^{1}$ \\ ${ }^{1}$ National Research Tomsk Polytechnic University, 634050 Tomsk, Russia
}

\begin{abstract}
Proper selection of the gating system for investment pattern is a long and laborintensive process that requires significant resources. The latest design technologies enable the calculation of the gating system and simulation of the casting process based on these calculations. Simulation and calculation of the gating system make it possible to determine defects which occur during the casting process at the design stage. The result of simulation is the distribution of flow and temperature velocity vectors. The process of cooling and crystallization is simulated, as well as a mold filling process. Analyzing these data and changing the characteristics of the gating system, it is possible to achieve the very high quality of castings.
\end{abstract}

\section{Introduction}

The technology of investment casting is frequently used in the manufacture of devices, parts of spaceaimed devices and particularly of body parts. Design of a cast part is technological if itis possible to produce the casting that meets the requirements of accuracy, surface roughness, physical and mechanical properties and structure of metal with the lowest production costs. The dimensions of the castings produced by the investment casting are maximally close to the dimensions of the completed part. Therefore, the cost of the product is shortened by the reduction of machining.

Foundry is one of the most highly-productive, fast, universal and cost-effective methods of metal ware molding. It was always important to create such technological processes which would ensure high operational life of parts by production of high-quality castings with the given structure and characteristics.

\section{Modeling}

The design of the gating system consisting of feeders, riser vents, downspures, sprue wells and bases plays an important role and has a direct impact on the quality characteristics of the casting. The quality of the casting process is directly related to the quality of an investment casting. The process of casting inevitably entails the defects of intimate structure of castings (cracks, sponginess, flux contamination and incomplete filling-up).

The process of casting and its quality depend on both the design of the gating system and its right selection. Construction of the gating system is currently based solely on the experience of the design

\footnotetext{
${ }^{\mathrm{a}}$ Corresponding author : muncko94@mail.ru
} 
engineer; therefore, there is a need in modeling, optimization and automation of a process of casting design using the CAD-systems to ensure the quality of casting. Simulation of the processes of casting, solidification and filling-up with the use of the latest technologies has become a necessity in the foundry industry [1].

Simulation of a casting process with the latest technologies makes it possible to eliminate possible casting defects in the early stages of the design which is a huge breakthrough in the field of mechanical engineering.

Thus, the modeling and design of the casting process using modern specialized computer programs help to reduce the production costs and increase the production and quality of the casting several times.

The crystal structure of the casting and the main processing, qualitative and operational characteristics depend on the number, shape, crystal growth rate and their initial orientation in the mold. Therefore, the important task in the field of foundry industry is the development of a methodology that ensures the monitoring of the structure and its characteristics, the heat and mass transfer, hydrodynamic casting processes and thermal-deformation interaction of casting and mold. The development of revolutionary new low-waste and non-waste technologies which provide a significant increase of operational, physical and mechanical characteristics of the cast metal is important as well [2]. New technologies will help to solve these problems.

The powerful software is designed in order to improve the efficiency and provide a high accuracy of numeric calculation. Every year, million tons of castings are produced worldwide, so the numeric calculations using the latest technology with the appropriate software are very necessary for the production of solid and large-sized castings [3].

Modern programs can read the STL file format of a solid geometric casting pattern. That is well since all CAD-systems work with the STL format and can fix the weakness of a STL file automatically without human intervention. Post-treatment may indicate the filling of a sample, 3D velocity change vector, 3D temperature distribution at any injection area and these operations are simple and easy [4]. Programs are able to select the different kinds of materials in order to define the frame properties during the numeric calculations of mold filling and solidification of the casting which allows the practical application of engineering analysis.

\section{Methodology}

The process of modeling and design of the gating system begins with the creation of a solid model, a functional surface model, drawings, technical specifications. New modern programs define the functional surfaces; dimensioning specifications, construction tolerances and boundary conditions using certain modules and based on these data, they model a parametric model wherein the depths of surfaces and geometrical dimensions are parametric. Engineer reuses parametric abilities of the gating systems models for the optimization of casting properties. The models are used to study the thermal, mechanical and structural characteristics.

That is a simulation model which will be a product model for various tests, particularly functional test, and based on these tests results the final model of the gating system is formed [5]. During the creation of a casting model the castability is changed by changing the geometry until the indicators of shrinkage, hole and recess filling meet the requirements.

\section{Main characteristics}

The main objective of the simulation of casting processes is the calculation of heat distribution in the investment casting with increase of time. This operation is carried out in specialized units. The fundamental heat transfer equation is determined by the thermal conductivity law. It is a specific differential equation of temperature $(T)$ and time $(t)$ relationship in the Cartesian coordinates $x, y, z$, where $\rho$ is a density, $C p$ is a thermal capacity and $\lambda$ - thermal conductivity [3]: 


$$
p c_{p} \frac{\partial T}{\partial t}=\frac{\partial}{\partial x}\left(\lambda \frac{\partial T}{\partial x}\right)+\frac{\partial}{\partial y}\left(\lambda \frac{\partial T}{\partial y}\right)+\frac{\partial}{\partial z}\left(\lambda \frac{\partial T}{\partial z}\right)+\dot{Q}
$$

Therefore, the time derivative of temperature at a point is determined by the flow of heat quantity and the source-heat dissipation term. It is possible to solve one system of linear equations for one time step using the discrete partial equations and final element analysis with boundary conditions.

The gap appears between the casting and the casting mold during solidification and liquid-metal cooling which affects their heat transfer and solidification conditions. In each case the gap differs depending on the molding method, the heating rate of the mold and the nature of its interaction with the metal induration.

The gap formation and modification is determined by three factors: the shrinkage of the casting, mold deformation during the molding cycle, the moldable extension of the under the action of ferrostatic pressure. The main contribution to the formation of the gap and the kinetics of its change is made by the first two factors. The calculations are made with the use of software based on different methods of calculation [2].

The temperature field of the casting mold varies with the change of time as well as the temperature field of the casting during the cycle of induration. The gap setting is the sum of the absolute values of the casting's shrinkage and deformation of the casting mold. The temperature distribution during filling of the form for one of the variants of the gating system design is shown in Figure 1.

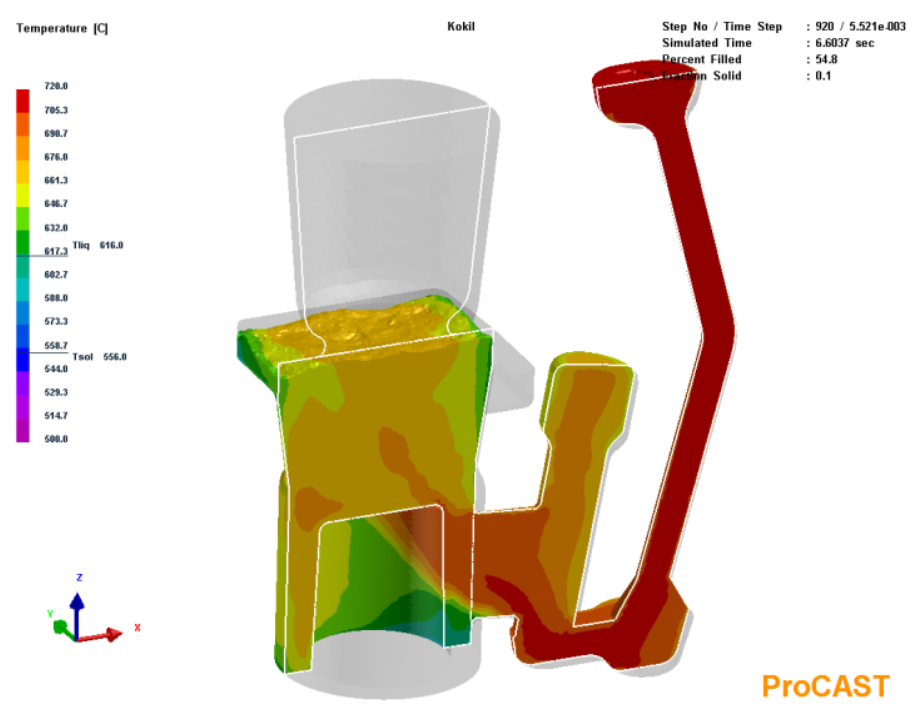

Figure 1. Filling the mold with the distribution of metal temperature. It is possible to define the temperature of liquid metal from the color using the grid.

The modern programs of computer modeling of foundry technologies based on physical theories of the thermal, diffusive, hydrodynamic and deformation phenomena are capable to imitate adequately many processes happening when filling with fusion of a form, at crystallization of a multicomponent alloy and further cooling of casting.

\section{Conclusion}

Computer simulation of casting processes and solidification has become a necessity in the foundry industry. The parameterization makes it possible to optimize quickly the casting properties of the casting which meet all the requirements within a very short time. Computer programs can read the STL file, a complex solid geometry, show the velocity vector, 3D velocity and temperature fields, the filling of a sample, distribution of mold filling temperature and solidification. 


\section{MATEC Web of Conferences}

It is possible to calculate the velocity and temperature fields for the laminar and turbulent flows during the filling of the mold and induration process. Numeric simulation can be used in order to predict the casting defects and improve the characteristics of the casting process for creation of body parts for space oriented equipment.

\section{References}

1. A. Swapnil, S. B. Ambekar, Dr. Jaju, Int. J. Eng. Res. and Gen. Scien. 2, 93 (2014)

2. E. I. Marukovich, V. F.Bevza, A. M.Bodyako, U. P.Hrusha, Cast. and Metal. 3, 63 (2011)

3. W. Junqing, S. Xun, G. Yang, W. Penghua, L. Hailan, B. Limei, S. Xinzhi, China Fdy., 179 (2008)

4. P. Malinowski, J. S. Suchy, J. Jakubsky, Arch. of metal. and ma. 3, 965 (2013)

5. C. Clauss, S. Schuch, R. Finocchiaro, S. Lankes, T. Bemmer, IPDPS, 306 (2006)

6. J. Jokinen, P. Makkonen, T. Saarelainen, E. Coatanéa, ICED 7, 28 (2007) 